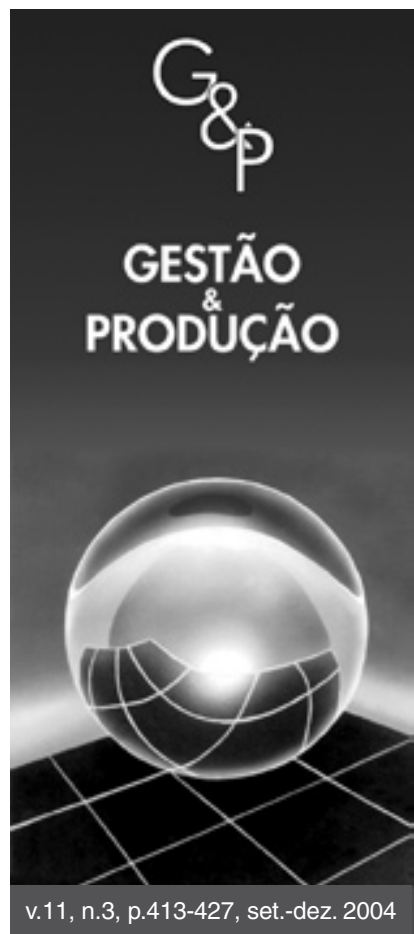

\title{
MUDANÇAS DE FORECAST NA INDÚSTRIA AUTOMOBILÍSTICA: INICIATIVAS PARA A ESTRUTURAÇÃO DOS PROCESSOS DE TOMADA DE DECISÃO E PROCESSAMENTO DA INFORMAÇÃO
}

\author{
Frederico Roldan \\ Dario Ikuo Miyake \\ Escola Politécnica da Universidade de São Paulo, \\ Departamento de Engenharia de Produção, \\ Av. Prof. Almeida Prado trav. 2, $\mathrm{n}^{\circ} 128$, Cidade Universitária, \\ CEP 05508-900, São Paulo, SP \\ e-mail: fredroldan@uol.com.br; dariomiy@usp.br
}

Resumo

Recebido em 02/7/04

Aceito em 17/11/2004

O presente artigo visa identificar que aspectos da literatura corrente sobre o processo de tomada de decisões, aliados à ferramenta de Mapeamento do Fluxo de Valor (MFV) - derivada da abordagem de manufatura enxuta -, podem ser aplicados ao processo de mudanças de forecast de produção na indústria automobilística. Proposições teóricas e suas implicações metodológicas são discutidas do ponto de vista prático, em um caso real no mercado brasileiro. São feitas recomendações visando melhorar este processo, trazendo maior clareza, objetividade e racionalidade, além de promover o fortalecimento da competitividade desta indústria e de sua cadeia de suprimentos. Desta forma, a idéia de combinar a aplicação da ferramenta de MFV, adaptada para processos administrativos, com sugestões baseadas em teorias descritivas e normativas da engenharia de tomada de decisão, se mostra promissora, podendo contribuir para melhorar a qualidade e eficiência no processo estudado.

Palavras-chave: cadeia de suprimentos, processo de tomada de decisão, mapeamento do fluxo de valor, indústria automobilística, Brasil.

\section{Por que mudar o forecast de produção?}

Em qualquer negócio, não existe dúvida de que um dos fatores de importância para o sucesso é o atendimento da demanda do produto ou serviço relacionado. Tal atendimento se caracteriza por uma série de fatores competitivos de negócio que se inter-relacionam e são responsáveis pela satisfação do cliente. Slack (1993) estabelece tais fatores de competitividade nas dimensões Custo (o preço correto), Qualidade (o produto correto), Velocidade (fazer rápido), Confiabilidade (fazer pontualmente) e Flexibilidade (mudar o que está sendo feito), seja em produto, mix, volume ou data de entrega. Muitos destes fatores competitivos estão relacionados ao objetivo de disponibilizar o produto ou serviço correto no momento que o cliente deseja.

Segundo o modelo de negócio tradicional da indústria automobilística, planejamento e programação dos processos produtivos e dos fluxos na cadeia de suprimentos baseiam-se em estimativas de demanda, o chamado forecast de vendas. Este por sua vez, dá origem ao forecast de produção, que ainda não pode ser considerado como o programa de produção para manufatura, pois, em todo o seu horizonte, ainda representa somente previsões sujeitas a ajustes e confirmações (horizonte que pode ser de várias semanas à frente da data atual). Quanto mais próximo da realidade o forecast, maior será o grau de atendimento da demanda real pela produção, que, efetivamente, for realizada naquele período. Caso contrário, a demanda deverá ser atendida por meio de produtos estocados, produzidos anteriormente, ou então se perderá a venda, muitas vezes, para a concorrência. Considerando-se que a demanda por veículos é dinâmica, é natural que tal forecast de vendas se altere ao longo do tempo e, 
conseqüentemente, o forecast de produção.

A Figura 1 representa, graficamente, estratégias opostas que uma empresa pode assumir, para o atendimento de sua demanda no tocante a tais alterações. Na Estratégia 1, assume-se nivelar o forecast de produção, atendendo à demanda de vendas pela formação de bancos de produtos, estocados ao longo do tempo. Já na Estratégia 2, procurase adequar o forecast de produção à demanda, alterandoo ao longo do tempo. Na primeira situação, busca-se uma maior estabilidade em toda a cadeia produtiva, porém a menor aderência entre o que se produz e o que se vende, torna necessária a manutenção de inventários de produtos acabados. Já na segunda estratégia, a aderência é maior, propiciando inventários menores de produtos acabados, por outro lado, gera maiores flutuações na cadeia produtiva (mudanças constantes na produção).

Práticas modernas de gerenciamento da cadeia de suprimentos, baseadas nos conceitos de manufatura enxuta, apregoam a relevância da racionalização dos inventários ao longo da cadeia (Womack e Jones, 1996). Consoante esta perspectiva, Fine (1999) aponta que a capacidade de reagir rapidamente à demanda, atendendo os clientes de forma mais precisa, representa uma das vantagens competitivas das empresas de sucesso modernas. Outros autores (Bronzo, 2004; Jones et al., 1997; Tyndall et al., 1998) indicam que a comunicação das informações e uso destas no planejamento das ações na cadeia de suprimentos de forma racional, em especial no tocante aos fluxos produtivos, sistêmica e não isoladamente, é essencial para o gerenciamento enxuto da cadeia e seus estoques.

Tais fontes indicam que no ambiente competitivo moderno, a adequação do forecast de produção à demanda representa uma vantagem competitiva. Para tanto, mostra-se vantajosa a prática de buscar-se esta aderência, ainda que implique em mudanças nos planos de produção. Tais mudanças devem, porém, ser feitas de forma racional, ponderando-se todos os fatores de influência e potenciais conseqüências. Segundo Shapiro (2001) e Wilding (1998), práticas que ajudem as cadeias de suprimentos a estabelecer processos mais racionais para lidar com fontes de incerteza e "caos", minimizando o "efeito chicote" nesta cadeia, contribuem para um melhor gerenciamento dos recursos, em especial, no tocante às variações de curto prazo. A competência na gestão das variações propor- ciona oportunidades para aumentar a competitividade da empresa e da cadeia em que esta está inserida, mas requer racionalidade na formulação dos ajustes, contemplandose os possíveis impactos sob uma perspectiva sistêmica de toda a cadeia.

Uma abordagem de negócio alternativa seria a da montadora de veículos aguardar pedidos de clientes e, com base nestes, produzir, exatamente, os veículos solicitados. Em outras palavras, build-to-order (BTO), ou seja, produzir para atender aos pedidos, em vez de produzir para estoque, e atender à demanda a partir deste. Este conceito alternativo à utilização de forecasts de vendas e produção tem atraído crescente atenção na indústria automobilística, por representar a oportunidade de poder melhor captar as demandas do mercado e atender aos anseios dos clientes, podendo constituir uma nova vantagem competitiva aos que conseguirem fazê-lo com a flexibilidade e eficiência necessárias (Holweg e Pil, 2001).

Em termos operacionais, a estratégia BTO requer velocidade no processamento das informações dos pedidos reais de clientes, nas operações de fabricação e montagem que irão gerar os produtos demandados, bem como na entrega final dentro de um prazo condizente. Para tanto, no caso da indústria automobilística, as plantas das empresas montadoras teriam de operar de uma forma bastante eficiente, apoiadas por cadeias de suprimentos, devidamente alinhadas e capacitadas para atender às solicitações puxadas a partir de cada pedido. Em tal contexto, torna-se crítica a capacidade de atender quaisquer pedidos de clientes, dentro da gama de produtos oferecida, operando com inventários reduzidos de componentes prontos.

Não obstante representar uma alternativa muito promissora e de, em alguns mercados como o de computadores, empresas como a Dell já terem evoluído bastante na sua implantação, tal modelo ainda não tem sido amplamente difundido no mercado automobilístico, justamente pelas dificuldades encontradas pelas montadoras em consolidar cadeias de suprimentos e de produção que satisfaçam às expectativas de funcionalidades, custo e velocidade, requeridas por um sistema BTO real (Chappell, 2004; Guyer, 2004). Face à acirrada competição que caracteriza o mercado automobilístico global, as montadoras têm buscado lead times de produção cada vez mais curtos,
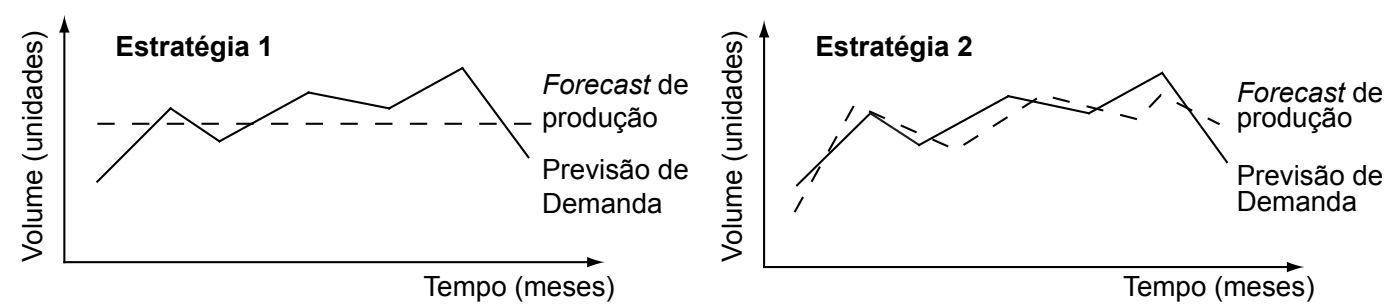

Figura 1. Estratégias de acompanhamento da demanda. 
revelando uma sensível evolução ao longo dos anos, porém, ainda, com resultados distantes daqueles esperados pelo mercado para a abordagem BTO (Miller, 2004).

Especificamente no mercado brasileiro, algumas grandes montadoras avançaram em direção à estratégia BTO, introduzindo a possibilidade de compra de alguns modelos de automóveis pela internet. Mas tal opção ainda se restringe a uma pequena parcela dos modelos oferecidos ao mercado e, em geral, são produzidos em plantas planejadas, de concepção inovadora, que se, por um lado, são abastecidas por fornecedores instalados mais próximos da montagem final na montadora, por outro, nem sempre puxam efetivamente os processos de produção destes, dado que, muitas vezes, a entrega just-intime é mascarada pela manutenção de estoques de componentes trazidos por aqueles de localidades distantes (Salerno et al., 2003). Além disso, ocorre da montadora oferecer somente uma variedade de veículos mínima que permita a manutenção de um estoque de produtos acabados, entre a montadora e o cliente final, sendo este atendido por tal estoque estratégico, e não, diretamente, por um sistema de produção capaz de produzir respondendo rapidamente à cada pedido.

Vale salientar, ainda, que, no mercado de carros de luxo, existem empresas como a BMW que, há muito tempo, já comercializam grande parte de suas vendas conforme os pedidos. Contudo, demoram até 2 meses para cumprir a entrega dos pedidos, prazo este muito além do que a grande massa de compradores de carros comuns está disposta a aceitar, ou seja, as montadoras e suas cadeias de suprimento têm ainda um longo caminho a percorrer até consolidarem sistemas BTO puros, com tempo de resposta aceitável (The Economist, 2004).

Frente a este panorama, é esperado que uma importante parcela das vendas das montadoras continue a depender da elaboração de forecasts de demanda e de produção, o que torna imperativo aos gestores aprenderem a lidar melhor com os processos de sua geração e ajustes. Para montadoras que ofereçam um mix de produtos bastante amplo, o planejamento com base em forecasts pode ser mantido em paralelo à adoção da estratégia BTO, dependendo do modelo e perfil de seu mercado. Tais perspectivas corroboram a necessidade de se buscar uma melhor estruturação dos processos de tomada de decisão e de processamento das informações, na elaboração e mudança de forecasts.

\section{Uma análise teórica do processo de tomada de decisões e seu fluxo}

Clemen (2001) define que toda decisão possui quatro pontos gerais de dificuldade: complexidade, incerteza inerente à decisão, objetivos múltiplos que se inter-rela- cionam e a possibilidade de diferentes perspectivas levando a diferentes conclusões de análise.

$\mathrm{Na}$ busca por melhores resultados, frente a estes fatores de dificuldade, ele define que é essencial diferenciar uma boa decisão de uma decisão de sorte. A primeira é embasada em um bom processo, que frente a todas as variáveis e influências envolvidas, busca equilíbrio em todos os fatores e provê o resultado mais racional, frente aos objetivos estabelecidos. Já, a segunda não necessariamente foi tomada com base em um processo racional e seguro, mas, sim, foi, simplesmente, uma decisão que, "por sorte", trouxe um bom resultado. Do ponto de vista normativo, a primeira difere da segunda por ser fruto de um processo elaborado de forma racional, que pode ser repetido e trará os mesmos resultados de análise. Assim, é preciso que se crie uma estrutura de análise, que proverá direção aos tomadores de decisão de qual o melhor caminho a seguir, com base em todas as influências e variáveis envolvidas. Este processo pode ser suportado por ferramentas conhecidas como "sistemas de apoio à decisão", que podem ou não ser complexas. O essencial é que a estrutura racional exista e propicie uma visão abrangente do que vem a ser o problema e quais os fatores envolvidos.

Já do ponto de vista descritivo, é importante entender como as decisões são tomadas em um dado contexto, e como se comportam os tomadores de decisão frente a diferentes situações e sob diferentes perspectivas. Bazerman (1994) apresenta uma série de vieses relacionados à forma como tomamos decisões, em geral, embasados em heurísticas, ou regras de simplificação. Tais vieses prejudicam o processo racional de tomada de decisão, trazendo subjetividade, parcialidade e falta de clareza para o processo. Conhecendo tais vieses, os tomadores de decisão podem, conscientemente, preparar-se melhor para este processo.

Bazerman (1994) classifica os vieses que afetam a tomada de decisão em diferentes classes segundo sua origem. A Tabela 1 apresenta um sumário destes vieses e aponta como eles ocorrem, afetando a tomada de decisões racional e alterando os resultados obtidos.

Tais vieses e alterações no processo de tomada de decisão estão presentes tanto em decisões tomadas por indivíduos, como por grupos, com inclinações mais fortes a algumas delas. Existem ainda vieses relacionados ao fato da decisão ser tomada por um grupo. Por exemplo, Bazerman (1994) indica que o grupo tende a nivelar suas decisões e sua postura frente ao risco, predominando a postura da maioria. Em grupos nos quais os indivíduos operam conjuntamente há algum tempo, existe uma tendência destes se adequarem uns aos outros, havendo pouca discussão, desafios e inovações em sua forma de decidir.

Numa decisão em grupo, existe a complexidade de várias posturas e objetivos de cada indivíduo que compõe 
Tabela 1. Vieses na tomada de decisão. (Fonte: adaptado de Bazerman, 1994).

\begin{tabular}{|c|c|c|}
\hline Origem & Tipo de viés & Como ocorre \\
\hline \multirow{3}{*}{ 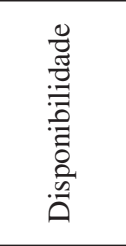 } & $\begin{array}{l}\text { Facilidade de } \\
\text { lembrança }\end{array}$ & $\begin{array}{l}\text { Julgamento da freqüência de eventos pela facilidade de sua lembrança em detrimento de fatos } \\
\text { mais difíceis de serem lembrados (menos marcantes, mais antigos). }\end{array}$ \\
\hline & $\begin{array}{l}\text { Rastreamento de } \\
\text { memória }\end{array}$ & $\begin{array}{l}\text { Julgamento da frequiência de eventos influenciado pela estrutura de memorização que privile- } \\
\text { gia aquilo que cada pessoa tem mais facilidade de lembrar. }\end{array}$ \\
\hline & $\begin{array}{l}\text { Associações pre- } \\
\text { sumidas }\end{array}$ & $\begin{array}{l}\text { Julgamento sobre a probabilidade de eventos conjugados, baseado em associações similares } \\
\text { anteriores, facilmente lembradas da experiência pessoal ou por influência social. }\end{array}$ \\
\hline \multirow{5}{*}{ 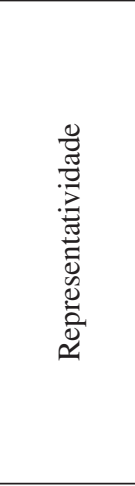 } & $\begin{array}{l}\text { Desconsideração } \\
\text { de valores base }\end{array}$ & $\begin{array}{l}\text { Julgamento sobre a probabilidade de um evento que ignora valores base (probabilidades co- } \\
\text { muns relativas a eventos similares), diante da disponibilidade de informações descritivas sobre } \\
\text { a situação analisada (muitas vezes irrelevantes). }\end{array}$ \\
\hline & $\begin{array}{l}\text { Desconsideração } \\
\text { do tamanho do } \\
\text { lote }\end{array}$ & $\begin{array}{l}\text { Julgamento que negligencia a importância do tamanho da amostra para a confiabilidade das } \\
\text { informações extraídas da amostra. }\end{array}$ \\
\hline & $\begin{array}{l}\text { Má concepção da } \\
\text { aleatoriedade }\end{array}$ & $\begin{array}{l}\text { Julgamento que uma seqüência de dados gerados ao acaso por um processo aparenta ser alea- } \\
\text { tória mesmo quando a amostra é pequena para validar esta hipótese estatisticamente. }\end{array}$ \\
\hline & $\begin{array}{l}\text { Regressão para a } \\
\text { média }\end{array}$ & $\begin{array}{l}\text { Julgamento que desconsidera o fato de que eventos extremos tendem a ser exceções e que em } \\
\text { tentativas subseqüentes as ocorrências tendem a se manifestar próximas da média. }\end{array}$ \\
\hline & $\begin{array}{l}\text { Falácia da conju- } \\
\text { gação }\end{array}$ & $\begin{array}{l}\text { Julgamento que tende a avaliar a probabilidade da ocorrência de eventos conjugados como } \\
\text { maior que a de um conjunto de eventos mais global do qual a conjugação faz parte. }\end{array}$ \\
\hline \multirow{3}{*}{ 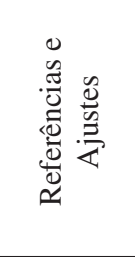 } & $\begin{array}{l}\text { Falta de ajuste das } \\
\quad \text { referências }\end{array}$ & $\begin{array}{l}\text { Julgamento baseado em valores de referência iniciais que deveriam ter sido ajustados para o } \\
\text { caso específico e que não sendo, provocam conclusões distorcidas. }\end{array}$ \\
\hline & $\begin{array}{l}\text { Conjunção e } \\
\text { disjunção }\end{array}$ & $\begin{array}{l}\text { Julgamento que tende a superestimar a probabilidade de eventos que ocorrem de forma conju- } \\
\text { gada e de subestimar a probabilidade de eventos que ocorrem de forma separada. }\end{array}$ \\
\hline & $\begin{array}{l}\text { Excesso de con- } \\
\text { fiança }\end{array}$ & $\begin{array}{l}\text { Julgamento baseado em excesso de confiança no acerto da decisão a ser tomada em ocasiões e } \\
\text { questões especialmente difíceis. }\end{array}$ \\
\hline \multirow{2}{*}{ 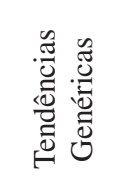 } & $\begin{array}{l}\text { A armadilha da } \\
\text { confirmação }\end{array}$ & $\begin{array}{l}\text { Julgamento baseado na busca por dados que confirmem a veracidade daquilo que se admite } \\
\text { como válido, negligenciando a busca de evidências que o desacreditem. }\end{array}$ \\
\hline & $\begin{array}{l}\text { Retrospectiva e } \\
\text { fluxo do conheci- } \\
\text { mento }\end{array}$ & $\begin{array}{l}\text { Julgamento sobre a previsibilidade de um evento com excesso de confiança após este ter ocor- } \\
\text { rido, além da não percepção de que muitas das informações que possuímos não são conheci- } \\
\text { das por outros, quando se procura prever o comportamento destes. }\end{array}$ \\
\hline
\end{tabular}

o grupo, e suas inter-relações. Para que se produza um resultado, é preciso que ocorra uma série de negociações, uma mescla de cooperação e competição entre os componentes do grupo, baseada nos objetivos individuais destes (que podem ou não coincidir com os objetivos do grupo). Tal situação dá origem a potenciais conluios entre os membros do grupo que definem sua postura com base em acordos paralelos ao processo de decisão do grupo como um todo. $\mathrm{O}$ entendimento deste processo e da sua estrutura, particular a cada situação e grupo, é essencial para que seus membros possam definir um processo racional de tomada de decisão e, assim, obter os resultados almejados.

Mais especificamente, analisando-se a tomada de decisões gerenciais no mundo dos negócios, alguns desses vieses e particularidades afastam a racionalidade do processo, segundo March e Shapira (1987). Os gerentes demonstram a tendência de ignorar probabilidades associadas a riscos, dando importância maior a sua magnitude de custos. Assim, resume-se a incerteza do processo decisório a custos atrelados a cada alternativa, sem se atentar às chances de tal fato ocorrer. Com isso, em muitas situações, administradores de negócio assumem riscos cuja magnitude de custos é baixa, porém com alta probabilidade de ocorrência, ao mesmo tempo que recusam riscos com alta magnitude de custos, mas com baixa probabilidade de ocorrerem. Tal postura, segundo um processo racional, pode muitas vezes mostra-se irracional, mas é observada em várias ocasiões.

Um outro ponto observado sobre o comportamento dos gerentes frente ao risco é o fato deles tenderem a perceber a incerteza como algo controlável, e que as chances de cada alternativa podem ser manipuladas e previstas pelo administrador. Esta postura, do ponto de vista racional, é irreal, uma vez que, por definição, se algo é incerto, não pode ser totalmente controlado e manipulado pelo tomador de decisão (March e Shapira, 1987; Clemen 2001).

Estes fatores analisados, se compreendidos e estruturados de forma adequada pelos tomadores de decisão, podem resultar em um processo mais racional que garanta consistência às decisões tomadas.

Com relação à estrutura do processo ou fluxo da toma- 
da de decisão, a partir dos anos 90, vários conceitos e técnicas de melhoria dos processos produtivos foram agregados sob a abordagem conceitual da chamada "manufatura enxuta", que emergiu a partir do chamado Sistema Toyota de Produção (Ohno, 1997), tendo sido globalmente divulgada por Womack et al. (1992). Num trabalho mais recente, os horizontes desta abordagem de racionalização foram ampliados por Womack e Jones (1996), que estabeleceram o conceito do pensamento enxuto. Tais conceitos apregoam as vantagens de um sistema racional e otimizado, baseado em inventários mínimos, fluxos contínuos de produção, atividades padronizadas, foco no cliente final, e eliminação de desperdícios ao longo de todo o processo. Ohno (1997) apresenta sete tipos globais de desperdícios presentes em um processo, que devem ser eliminados: superprodução (fazer mais do que o necessário), espera (recursos desperdiçados), transporte desnecessário (não requeridos pelo cliente), processamento exagerado (mais do que o necessário para satisfazer o cliente), inventário (recursos despendidos desnecessariamente), movimentação (pessoas ou objetos sendo movimentados sem necessidade), e retrabalho (refazer o que já foi feito, para corrigir algo).

Uma das ferramentas desenvolvidas, para apoiar a implementação da manufatura enxuta, é o Mapeamento do Fluxo de Valor, que busca mapear o fluxo de um processo produtivo (o chamado Mapa do Fluxo de Valor Atual), focalizando sua atenção naquilo que o cliente final procura, detectando desperdícios nos processos existentes, e propondo mudanças no fluxo, para que tais desperdícios sejam eliminados e o processo, como um todo, seja melhorado, aproveitando-se melhor os recursos utilizados. Tal ferramenta foi apresentada de forma conceitual por Womack e Jones (1996), porém melhor explicitada e demonstrada de forma prática por Rother e Shook (1999). A literatura sobre suas aplicações sempre se concentrou em processos de manufatura, sendo sua utilização em processos administrativos somente proposta recentemente por Hines et al. (2000) e Tapping et al. (2002), que estenderam a aplicação dos conceitos básicos originais aos fluxos de informações e documentos que caracterizam tais ambientes.

\section{Observando um caso real}

A discussão da consideração prática dos conceitos teóricos e das técnicas de análise estruturada, que são abordados neste trabalho, baseia-se na verificação da pertinência de associá-los e aplicá-los a uma situação real em uma montadora de veículos, sediada no $\mathrm{ABC}$ paulista. $\mathrm{O}$ problema objeto de estudo é o processo de realização de mudanças de forecast de produção desta montadora no qual um dos autores pôde participar, pelo período de pelo menos 24 meses. Esta experiência possibilitou verificar como um processo de alteração ocorre realmente, e como pode ser relacionado com os pontos indicados pelas teorias sobre o processo de tomada de decisões, servindo de base para as considerações práticas realizadas neste trabalho.

O desenvolvimento da pesquisa se deu em duas etapas, sendo que ambas requereram a adoção de visão sistêmica para a leitura e análise da situação observada. Inicialmente, a sistemática de tomada de decisão, que baliza do ponto de vista lógico e organizacional o processo objeto de estudo e que determina a qualidade das decisões que são geradas, foi levantada e analisada no segundo semestre de 2003. As análises e recomendações de melhoria, elaboradas nesta etapa, são apresentadas nas seções $3.1 \mathrm{e}$ 4.1. Em seguida, num momento em que a empresa, onde o processo objeto de estudo foi investigado, sentia, de forma mais acentuada, os problemas intrínsecos à dinâmica deste processo, face às revisões de forecast, motivadas pelo significativo aumento das vendas previstas com o aquecimento da demanda, o fluxo do processamento de informações pelas áreas envolvidas foi investigado e analisado, entre abril e maio de 2004. Nas seções 3.2 e 4.2, são apresentadas e discutidas as análises e recomendações de melhoria, elaboradas nesta frente de pesquisa.

A Figura 2 apresenta de forma genérica o fluxo adotado para as mudanças de forecast pela montadora, que gera o programa de produção interno e o programa externo, para as entregas pelos fornecedores de sua cadeia de suprimentos. O processo ocorre oficialmente com regularidade mensal, mas com certa freqüência são realizadas revisões intermediárias, a critério da direção da organização.

Tal processo dá origem a mudanças dentro da cadeia de suprimentos, tanto interna como externamente, uma

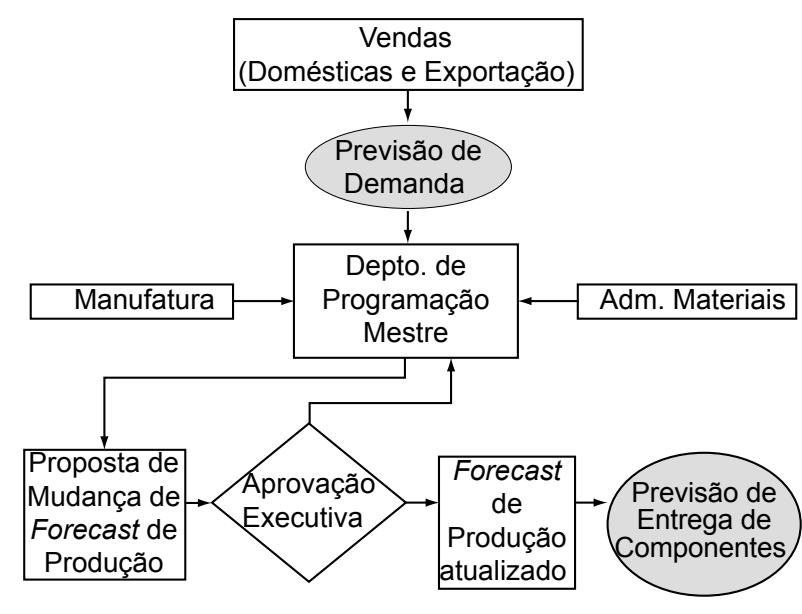

Figura 2. Fluxo de tomada de decisão para mudanças de forecast. 
vez que determina o que deve ser produzido em cada período, com um horizonte de 40 semanas à frente da data em que a revisão ocorre. Tais mudanças podem representar variações como as observadas na Figura 3, em que cada uma das colunas, em um dado mês, representa a previsão de entregas de um dado componente automotivo, destinado a um dado veículo para aquele mês, enviada ao fornecedor nas datas indicadas na legenda.

Todo o processo ocorre no período de uma semana, com início às terças-feiras, quando Vendas (mercados doméstico e exportação) apresenta sua proposta de mudança ao atual programa de produção. A área de Programação Mestre desenvolve, então, alternativas de planos de produção que são passadas para Manufatura (responsável pela cadeia produtiva interna à organização) e Administração de Materiais (ou simplesmente Materiais, responsável pela cadeia de suprimentos, abrangendo todos seus fornecedores). Ambas áreas devem retornar com suas análises até a metade do dia de quinta-feira. Tais análises, na verdade, são propostas ou posicionamento para atender aquilo que Vendas está buscando. Devem conter eventuais custos necessários ao atendimento da consulta, como mão-de-obra extra ou adicional (internos e de fornecedores externos), fretes especiais para acelerar o recebimento de materiais, eventuais excessos de inventário e materiais obsoletos, gerados pela redução das quantidades programadas de algo já em processo de produção ou recebimento. Ou mesmo estimativas de perdas de produção ou produção de unidades incompletas, pela impossibilidade em responder às mudanças. No caso de uma eventual impossibilidade de se atender ao pedido, ou

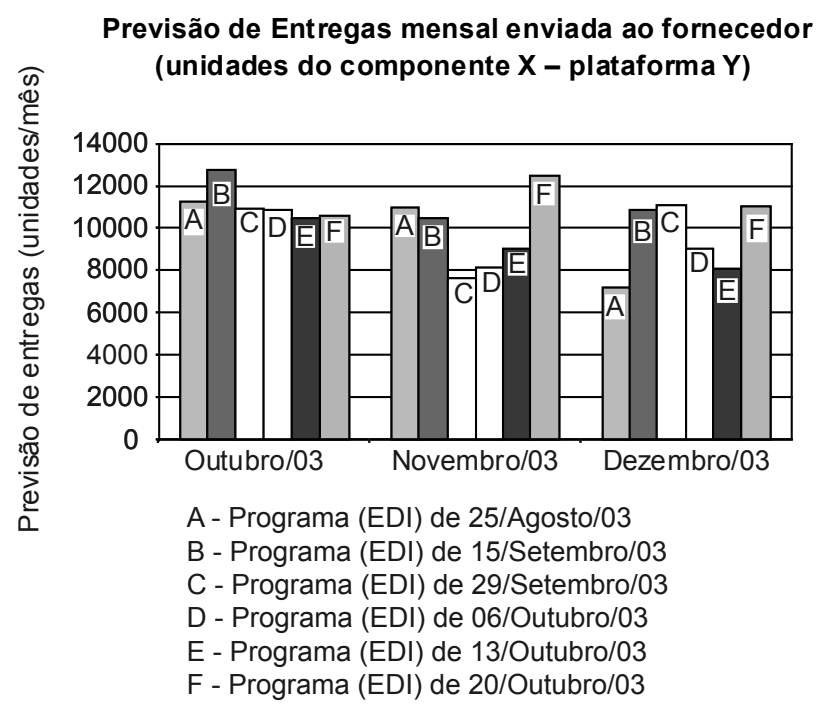

Figura 3. Exemplo de variações de forecast de produção para fornecedores (elaborada com base em dados de um fornecedor de primeira camada da cadeia de suprimentos). mesmo variações deste, as áreas devem apresentar, então, suas restrições e, se possível, condições e requerimentos para solucioná-las.

De posse dos resultados da análise destas áreas, todos os demais grupos envolvidos verificam o impacto das análises apresentadas em sua função, inclusive Finanças, entre a tarde de quinta-feira e a manhã de sexta-feira. Entre esta sexta-feira e segunda-feira, deve haver o acordo final de todas as partes e aprovação pela alta direção da empresa. Tal aprovação deve, preferencialmente, ocorrer na própria sexta-feira para que as mudanças acordadas sejam efetuadas no sistema de programação de materiais (MRP) para todos os fornecedores, em tempo para a sua atualização, que ocorre em todos os finais de semana.

\subsection{Como a tomada de decisões ocorre}

A observação deste processo e de sua estrutura à luz das teorias referentes ao processo de tomada de decisão (Bazerman, 1994; March e Shapira, 1987), revelou alguns vieses que podem prejudicar a racionalidade do processo. Primeiro, dado o tempo exíguo para se realizarem as análises necessárias, tanto as áreas de Manufatura como as de Materiais, precisam se valer de heurísticas para suas decisões, baseadas em casos ou problemas passados mais recentemente, denotando o viés da Facilidade de Lembrança. Como a área de Materiais lida com aproximadamente 450 fornecedores em suas várias cadeias de suprimentos, é impossível consultar todos, em algumas horas, sobre as mudanças em discussão.

Também pela restrição do tempo disponível para a análise e pela falta de uma ferramenta ou sistema de apoio à decisão, há uma tendência em extrapolar conclusões e cálculos relativos a uma situação específica, incorrendo nos vieses da Falta de Ajuste de Referências e da Regressão para a Média.

Apesar do processo de atualização requerer a apresentação de custos e eventuais problemas ou riscos para o atendimento da consulta, tais cálculos são avaliados e considerados em desacordo com o sugerido pelas teorias da Tomada de Decisão. Em especial, incertezas são apresentadas somente com sua magnitude de custos, sem suas respectivas probabilidades, inviabilizando uma análise racional e completa das alternativas (Clemen, 2001; March e Shapira, 1987). Além disso, o fato da consulta não ser repassada a todos os participantes da cadeia de suprimentos indica uma tendência em acreditar ser possível controlar as incertezas ligadas ao processo. A comunicação de tal informação em toda a cadeia é tida como uma prática saudável e racional (Jones et al., 1997; Tyndall et al., 1998).

Dado que cada área possui sua própria crença referente às mudanças sugeridas, é natural que as análises trazidas sempre contemplem dados e fatos que confirmem a 
postura de quem as traz. Ainda que inconscientemente, existe parcialidade na coleta de dados para análise, trazendo o risco do viés da Armadilha da Confirmação.

Após a implementação de uma mudança, cujos impactos em cada área são geralmente difíceis de prever com precisão, existe uma grande pressão para explicações sobre o porquê dos impactos reais obtidos. Quando estes são negativos, tal questionamento é feito com uma visão de que estes poderiam ter sido previstos na época da análise e a decisão tomada de forma diferente. Assim, o conceito de risco e incerteza perde seu sentido, com a chance de se incorrer no viés da Retrospectiva.

Por fim, além destes vieses, Bazerman (1994) apresenta também vieses relacionados ao processo de tomada de decisão em grupo. A percepção de risco apresentada por uma área em algumas situações é diluída pelo grupo (fato agravado pela falta de probabilidades atreladas aos riscos). Existe pouco desafio e discussões profundas entre as áreas, prevalecendo a busca, desde o princípio, por concordância, o que dificulta o desenvolvimento de idéias e soluções criativas, uma característica típica do viés de Groupthinking, agravada pelo viés das Negociações Políticas e Coalizões entre os grupos (numa busca por objetivos de suas áreas, que não necessariamente refletem os objetivos da organização como um todo).

Trata-se, portanto, de um processo em grupo bastante amplo e complexo que depende de uma alta quantidade de informações, processadas por uma teia de relações interpessoais, da qual se requer uma interação rápida e dinâmica, o que, contudo, muitas vezes, não acontece, quer seja por falta de uma ferramenta de comunicação que integre todos os envolvidos, quer seja pela falta de estruturação do processo como um todo.

\subsection{0 fluxo do processo de tomada de decisão}

Com relação ao fluxo do processo propriamente dito, numa primeira análise podem se encontrar alguns desperdícios similares aos apontados por Ohno (1997) em processos de manufatura, como desperdícios de tempo com esperas por informações, retrabalho de tarefas, por conta de mudanças no tratamento das informações, e até desperdícios de processamento, por parte das áreas que processam os dados recebidos e realizam análises de impactos (ainda que parciais e incompletas), que posteriormente acabam não sendo utilizadas adequadamente, por falta de um processo e ferramenta apropriados.

Mais especificamente, em relação a processos administrativos, como no caso estudado neste artigo, Hines et al. (2000) apontam vários desperdícios que podem ser identificados pelo mapeamento destes processos: departamentos gargalo para análise, múltiplas iterações entre os participantes do processo, proliferação de pontos de confirmação de informação, múltiplas cópias e distribuições de documentos (ou neste caso, informações eletrônicas), falta de rastreabilidade apurada da análise feita em cada caso, e da racionalidade utilizada em cada decisão (o que, conforme apontado por Bazerman, 1994, caracteriza um viés na tomada de decisão). Além disso, tais processos estão sujeitos a eventuais tentativas de aceleração por vias não usuais ou oficiais, por exemplo, aproveitando-se da hierarquia para forçar uma determinada decisão.

Hines et al. (2000) propõem a análise das atividades que constituem um processo e sua classificação, em atividades que agregam valor para o cliente final (VA, Valor Agregado), que não agregam valor (SVA, Sem Valor Agregado) e que são necessárias ao processo (muitas vezes por razões procedimentais ou estruturais), porém não agregam valor ao cliente final (NSVA, Necessárias Sem Valor Agregado). A busca por processos melhor estruturados implica, portanto, num esforço contínuo para destinar a aplicação dos recursos disponíveis em atividades VA, eliminando tanto as atividades SVA como as NSVA, sempre que possível. Tal notação e conceitos podem ser aplicados no caso objeto de estudo, objetivando melhorias no processo de tomada de decisão em questão, conforme é apresentado a seguir.

\section{0 que pode ser melhorado?}

A busca de melhorias no processo de decisão pode ser segmentada em duas frentes de trabalho principais: a melhoria da qualidade deste processo, bem como do fluxo do processo propriamente dito. A primeira, por abordar a estruturação e os aspectos comportamentais relacionados à tomada de decisão, traz melhorias na consistência e racionalidade do resultado final da decisão. Já a segunda, foca a obtenção de um processo mais "enxuto", rápido, em que se tenha menos etapas desnecessárias e um melhor aproveitamento dos recursos utilizados. Uma proposta completa de melhoria deve trazer a visão de ambas as frentes descritas, conforme ilustrado na Figura 4.

$\mathrm{O}$ tratamento de cada uma destas perspectivas para a melhoria do processo requer a aplicação de conceitos e ferramentas específicos. Conforme sugere a Figura 4, o presente artigo articula uma abordagem de análise e melhoria, embasada em princípios e ferramentas provenientes da chamada escola da "manufatura enxuta" - originária do chamado "Sistema de Produção Toyota" (Ohno, 1997, Womack et al., 1996) -, com seus conceitos tradicionalmente aplicados a processos de manufatura revistos e adaptados para processos administrativos, e elementos extraídos da literatura sobre o processo de tomada de decisão, tanto do ponto de vista normativo (Clemen, 2000) como descritivo (Bazerman, 1994). Ainda que tais fren- 
tes de análise sejam discutidas separadamente na literatura, as seções seguintes ilustram como sua aplicação em conjunto, no tratamento do problema objeto de estudo, tem a oferecer soluções mais consistentes.

\subsection{Melhorando a qualidade do processo}

A consideração da qualidade do processo requer a focalização de esforços na estruturação analítica do processo ou problema, visando o desenvolvimento de um processo racional para a tomada de decisão, que contemple todos os fatores de impacto e influência. Para tal processo de análise, Clemen (2001) propõe a construção dos chamados Gráficos de Influência referentes a cada situação. A criação destes gráficos possibilita a visão clara e racional do que afeta o processo, dando elementos para uma melhor compreensão da situação por todos os participantes, além de servir de base para a eventual modelagem de um sistema de apoio à tomada de decisão.

A Figura 5 resume de uma forma geral e simplifica- da o gráfico de influências para o caso considerado. Por meio dele, pode-se verificar quais as áreas e fatores que impactam a decisão e seus resultados, inclusive quais as incertezas ligadas ao processo.

$\mathrm{Na}$ continuidade da análise, cada uma das áreas que provê dados para a tomada de decisão também pode ser representada por um gráfico de influências, tal como exemplificado na Figura 6. O entendimento da totalidade dos gráficos de influência do processo e de suas implicações permite que os participantes tenham um melhor entendimento de quais informações são importantes em suas considerações, e quais os riscos e incertezas existentes.

Isso possibilita o desenvolvimento de ferramentas como Árvores de Decisão e até de sistemas de apoio à tomada da decisão, contribuindo para a repetitividade do processo. Neste caso, a elevada quantidade e complexidade das informações, a rapidez requerida para análise, e a alta freqüência com que o processo deve ser realizado,

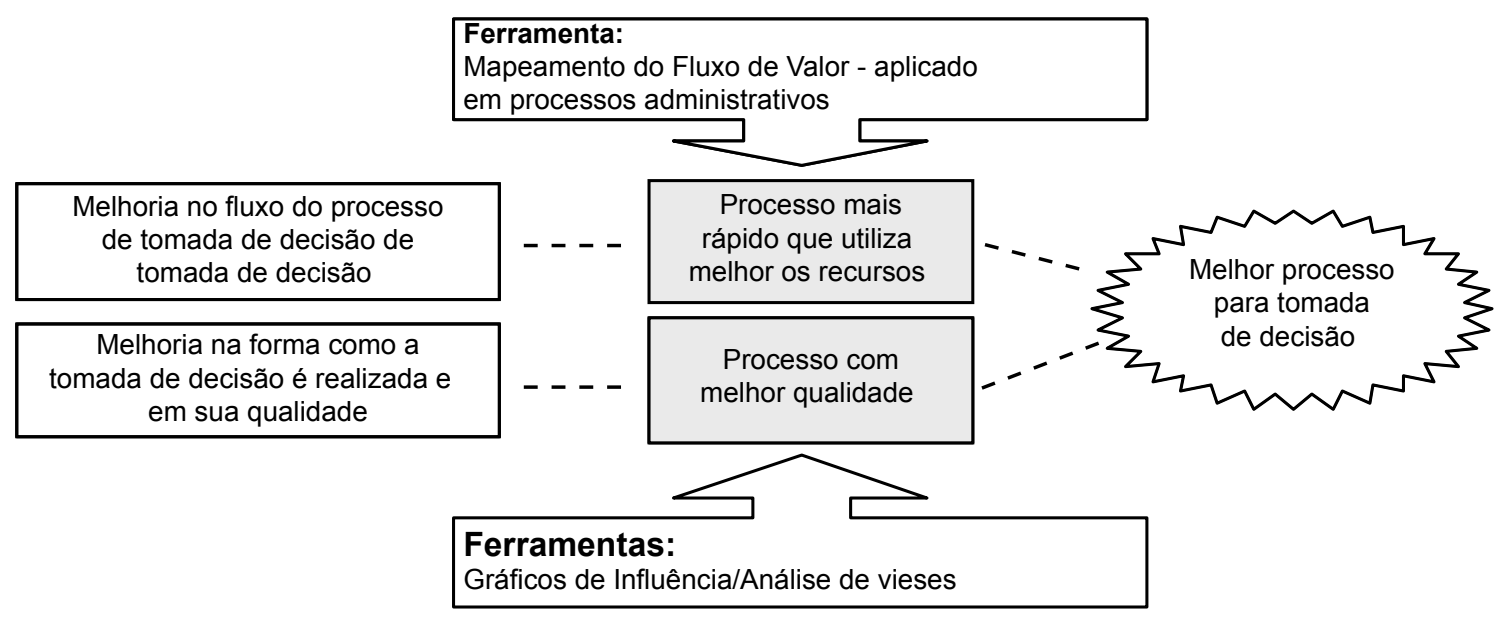

Figura 4. A visão de melhoria do processo de tomada de decisão.
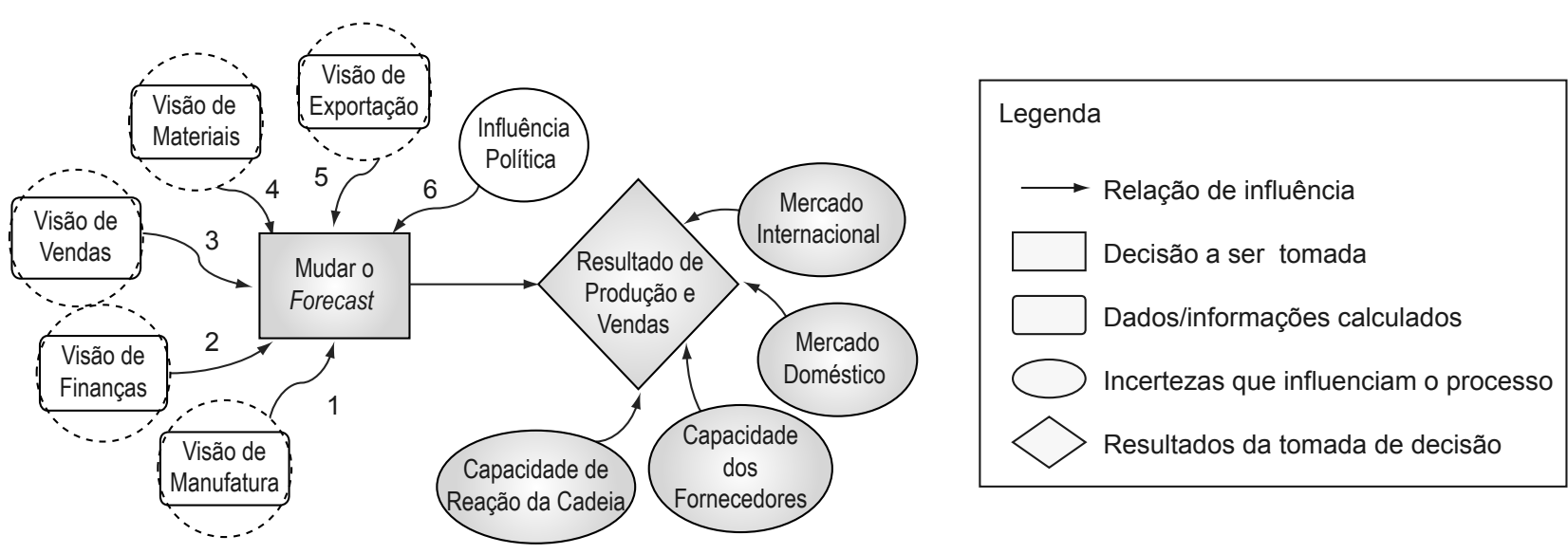

Figura 5. Gráfico de influência geral e simplificado. 


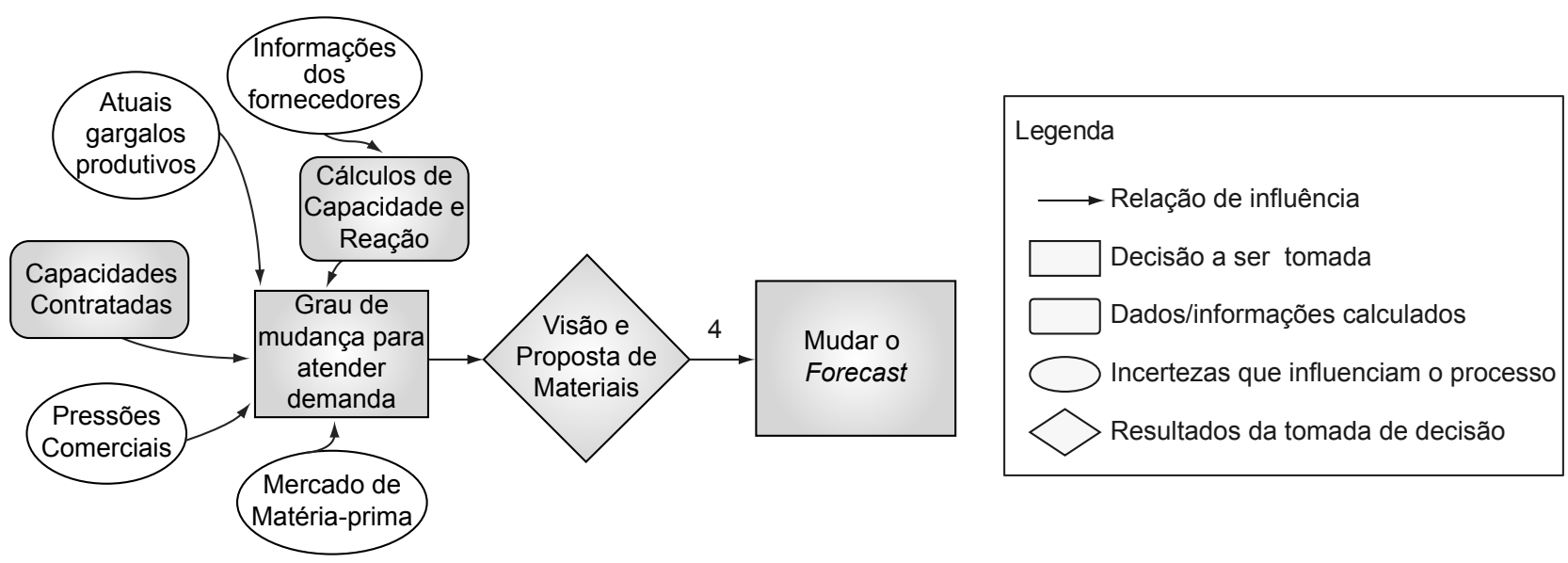

Figura 6. Desdobramento das visões funcionais - Exemplo da Adm. de Materiais.

justificariam o desenvolvimento de tal sistema (que traria estrutura e maior racionalidade ao processo). Como uma proposta prática neste sentido, em vez de se utilizar correio eletrônico nas comunicações entre as áreas sobre os diversos dados a serem analisados, poderia ser criado um sistema eletrônico de compartilhamento em tempo real, quer seja uma página na rede eletrônica da empresa, ou uma outra ferramenta eletrônica, como bancos interligados (ex. Lotus Notes), em que todos pudessem colocar seus dados rapidamente, e checar os demais dados colocados, facilmente eliminando trocas de mensagens eletrônicas entre várias pessoas. Esta prática agiliza a comunicação e elimina problemas de inconsistência, como a não distribuição para alguns membros do grupo, demora na transmissão, e congestionamento da rede de correio eletrônico.

Com base nos gráficos de influência apresentados, é possível desenvolver uma ferramenta de análise que permita tanto a documentação correta dos dados que influem em cada decisão, vindos de diferentes departamentos, como o processamento abrangente destes dados. Por exemplo, Finanças poderia criar uma ferramenta que, a partir das considerações das áreas envolvidas, pudesse projetar os diferentes impactos que sucederiam de suas influências (mapeadas pelos gráficos de influência), a probabilidade de risco destes impactos, bem como formalizar uma análise similar ao de uma árvore de decisão para cada processo de mudança, trazendo racionalidade, estrutura e rastreabilidade ao processo de decisão.

Outra melhoria importante do processo é a adoção de uma linguagem comum pelas áreas envolvidas. A proposta de mudança é feita por Vendas em termos de veículos e seus modelos. Manufatura trabalha com unidades a serem produzidas (equivalentes aos veículos usados por Vendas). Materiais trabalha com peças e custos operacionais (inventário e fretes especiais). Finanças busca converter tudo em termos de custos ou valor monetário. $\mathrm{O}$ ideal seria que qualquer proposta de mudança fosse transformada em informações manipuláveis por todas as áreas e pela cadeia de suprimentos envolvida, que tal, como Materiais, planejasse com base em quantidades de peças. Esta interação pode também ser suportada por uma ferramenta de comunicação e compartilhamento de informações.

Ainda do ponto de vista de melhoria na qualidade do processo, é importante que se abordem ações que possam influir na perspectiva comportamental do processo. Isso implica em buscar uma melhor educação de todos os envolvidos, trazendo-lhes a consciência dos vieses mais comuns a que um processo de decisão pode estar sujeito, conforme autores como Bazerman (1994) e March e Shapira (1987). Recomendações podem ser feitas a fim de orientá-los a não incorrerem em vieses de julgamento por meio de treinamento, alterações na estrutura do processo e implementação de procedimentos de tomada de decisão mais eficazes.

Assim, recomenda-se que o histórico de mudanças anteriormente efetuadas, se admitido como referência para fins de análises atuais, seja ajustado a fim de evitar o viés de Ajuste de Referência. Em especial, as incertezas e riscos devem ser apresentados e analisados com base não somente em sua magnitude de custos, mas também em sua probabilidade. Toda a organização deve aprender a trabalhar com tais dados, considerando-os em suas análises, sem pretender controlar todos riscos e reconhecendo a existência de incertezas.

No que tange aos elementos que devem participar do processo, deve-se buscar uma participação equilibrada de todas as áreas, e a inserção dos participantes de toda a rede de suprimentos, formada pelas diferentes cadeias (se não todos, ao menos os mais críticos e estratégicos para a montadora), uma vez que são diretamente afetados pelas 
mudanças em questão. Finanças, por exemplo, deve ter um papel mais marcante no processo, com mais tempo para sua análise, e contar com ferramentas que auxiliem na avaliação dos impactos financeiros de cada alternativa para a organização. Para que os participantes da rede de suprimentos possam participar efetivamente, provendo dados e informações relevantes à tomada de decisão, não se limitando a receber os resultados do processo de mudança, ferramentas de suporte e processos formais devem ser criados.

Dada a importância do processo de mudança de forecast para a competitividade no mercado e seu alto impacto em toda a cadeia de suprimentos, mostra-se válida a idéia de se investir no desenvolvimento de ferramentas de apoio, que não somente documentem a experiência de cada repetição do processo, mas que também incorporem o conhecimento desenvolvido na organização que, posteriormente, possibilitará atualizar e refinar a racionalidade sobre a qual a tomada de decisão se apóia (Bazerman, 1994).

\section{2 - As melhorias no fluxo do processo}

No que diz respeito ao fluxo da tomada de decisão, o processo de mudança de forecast de produção requer maior agilidade e velocidade. Isso pode ser conferido por práticas que racionalizem a fluidez e a utilização dos recursos, em linha com os princípios propagados pelo pensamento enxuto. Embora tais princípios sejam cristalinos, a iniciativa de tornar um processo mais enxuto, muitas vezes esbarra na dificuldade de planejar a introdução das práticas ditas enxutas. Segundo Rother e Shook (1999), esta barreira pode ser contornada pela aplicação da ferramenta do Mapeamento do Fluxo de Valor (MFV). Embora, tradicionalmente, esta ferramenta venha sendo aplicada a processos de manufatura em que se tem um fluxo físico de peças sendo processadas, por uma seqüência de operações industriais, tentativas de sistematização da sua aplicação em ambientes administrativos têm, recentemente, emergido para, justamente, facilitar aqueles que procuram um meio prático que lhes permita enxergar o fluxo de atividades e informações existente, de forma análoga aos mapeamentos tradicionais (Hines et al., 2000, Tapping et al., 2002).

A aplicação da metodologia inicia-se pela etapa de desenho do chamado "mapa do estado corrente", que é o mapeamento das atividades que compõem o processo, identificando-se quem as realiza, os tempos de processamento e de espera incorridos tanto durante uma atividade como entre atividades, e o fluxo de informações entre participantes, com o cliente final do processo no topo do mapeamento. É recomendável realizar e confirmar este mapeamento inicial com a participação das diversas pessoas envolvidas no processo focado.

Com base neste levantamento do estado corrente, os desperdícios existentes na condução das atividades do processo são apontados conforme a perspectiva sugerida por Hines (2000), de adaptação dos preceitos estabelecidos originalmente por Ohno (1997), no contexto dos processos de manufatura, para o contexto dos processos administrativos. Os desperdícios assim apontados evidenciam os recursos que estão sendo utilizados sem agregar valor ao processo, e indicam que pontos podem ser alterados ou até eliminados em cada atividade (ou como estas interagem), de modo a racionalizar a utilização dos recursos para a obtenção dos resultados demandados pelo cliente final.

Nesta etapa, é importante que cada participante que tenha algum contato com o fluxo do processo, entenda a função de todas as atividades do processo, suas necessidades de recursos e os dados de entrada requeridos, para poderem num passo seguinte identificar o que é realmente essencial para o processo, e o que poderia ser descartado e "economizado". Este passo é um exercício experimental, que depende da iniciativa e criatividade daqueles que participam da discussão sobre o "estado futuro" desejado, não existindo uma solução única e final para as possíveis melhorias.

No trabalho de redesenho do fluxo, delineia-se a construção de um novo fluxo para o processo atividade por atividade, dando origem ao chamado "mapa do estado futuro" em que todas as ações possuiriam um sentido bem definido do ponto de vista de agregação de valor para o cliente do processo. Este mapa permite, assim, visualizar o objetivo de melhoria a ser buscado. A fim de garantir que a reconfiguração do processo proposta no "mapa do estado futuro" seja alcançada, é essencial que as ações que podem conduzir a passagem do "estado corrente" para o "estado futuro" sejam documentadas, compondo um plano de implantação, com responsáveis identificados e prazos a serem cumpridos (Rother e Shook, 1999).

Um trabalho de exploração da aplicação do MFV foi então realizado na montadora em que o processo considerado ocorre, com a efetiva participação de um dos autores deste trabalho, que exerceu o papel de seu principal condutor. Para isso, este autor procurou, inicialmente, familiarizar-se com a aplicação do MFV, participando de um treinamento genérico, ministrado por um instrutor especializado na disseminação desta ferramenta em abril de 2004. Em maio de 2004, consultou então uma equipe multifuncional, constituída de representantes de 6 diferentes áreas que são envolvidas no processo de mudança de forecast e obteve as informações requeridas no mapeamento.

O mapa do fluxo do processo atual assim levantado é apresentado na Figura 7, utilizando-se a notação gráfica definida por Rother e Shook (1999) e Tapping et al. (2002). Nesta figura, os valores dos tempos de processo 
de cada atividade, dos tempos de espera e do índice de Acerto na Primeira Tentativa são identificados, respectivamente, por PT (Process Time), WT (Waiting Time) e FTQ (First Time Quality).

Ainda na Figura 7, o quadro referente a cada atividade do processo classifica se a etapa agrega valor (ou não), conforme o procedimento de análise proposto por Hines (2000) e os pressupostos assumidos no mapeamento. O mapeamento realizado revelou desperdícios no processo, tais como: esperas, áreas gargalo, múltiplas interações entre áreas, retrabalho, comunicação deficiente e repetitiva e falta de rastreabilidade das informações. Alguns destes estão demarcados com destaque na figura.

Para dar prosseguimento à iniciativa de racionalizar o fluxo mapeado, os desperdícios identificados devem ser analisados procurando-se obter meios específicos para eliminá-los, sobretudo focalizando esforços de melhoria em atividades que não oferecem valor ao cliente final e melhorando aquelas que o fazem. As propostas de melhoria são portanto focadas, prioritariamente, nas atividades Sem Valor Agregado (SVA) que devem, sempre que possível, ser eliminadas por não trazerem qualquer valor para o cliente do processo. Em seguida, as atenções devem recair sobre as Necessárias Sem Valor Agregado (NSVA), que, apesar de identificadas a priori como necessárias ao processo, devem também ser reduzidas ou eliminadas, sempre que possível (Hines 2000).

A principal motivação desta aplicação piloto foi obter um novo fluxo para o processo em questão, tal como apresentado na Figura 8, segundo o qual, os recursos seriam melhor aproveitados e os tempos de espera das atividades - que claramente não agregam valor ao cliente final - poderiam ser diminuídos. Para o delineamento do novo processo, o autor condutor do mapeamento voltou a consultar a equipe multifuncional e, com as visões críticas e proposições colhidas de cada elemento, buscou direcionar os recursos ao que é realmente importante para o cliente final do processo, para que o processo ocorra de um modo mais eficiente, trazendo os resultados esperados.

O novo fluxo delineado já prevê a eliminação de atividades consideradas SVA, para se buscar um melhor aproveitamento dos recursos existentes. Dado que um ciclo do processo é iniciado e completado num período de uma semana, e que as previsões de entrega de componentes para os fornecedores são atualizados semanalmente, não existe um grande benefício em se reduzir o tempo de ciclo do processo. O ideal neste caso, é que se aloque mais tempo de processo (e não de espera) à realização mais cuidadosa das atividades que agregam valor, beneficiando o processo como um todo. Em especial, é de grande valia, alocar mais tempo aos departamentos responsáveis por desenvolver as análises pertinentes que devem subsidiar as decisões de mudança do forecast de produção, como a área de Materiais, que precisa de tempo para poder contatar um grande número de fornecedores nas várias cadeias de suprimentos, e a de Finanças, que deve ter tempo suficiente para preparar suas análises, frente aos possíveis impactos apontados por cada área envolvida.

A comparação apresentada na Figura 9 indica que o novo (ou futuro) fluxo atenderia estes requisitos, concentrando o tempo disponível em atividades que agregam valor, utilizando os recursos disponíveis de forma mais adequada, e promovendo um processo de tomada de decisões e mudança de forecast, fundamentado em informações de melhor qualidade, coletadas com um tempo maior.

\section{Conclusão e implicações futuras}

É possível estruturar o processo de tomada de decisão para mudanças de forecast de produção na indústria automobilística de uma forma objetiva e racional, seguindo os preceitos das teorias sobre tomada de decisão e identificando oportunidades para a racionalização deste processo, tanto sob a perspectiva da qualidade de informação resultante de aspectos comportamentais, como sob a perspectiva do próprio fluxo do processo (rapidez, fluidez e utilização correta dos recursos).

Dado que este processo é um fator crítico para a competitividade neste mercado, é essencial que se traga mais clareza sobre o modo como ele tem sido conduzido na indústria. Este artigo apresentou como tal processo de tomada de decisão tem sido praticado numa montadora, e o analisou à luz de conceitos e ferramentas de análise recomendadas pela literatura, apontando oportunidades de melhoria, pelo treinamento dos elementos envolvidos, melhor estruturação do problema de mudança do forecast, de modo a trazer maior clareza sobre os fatores que influenciam o processo de decisão e sobre os potenciais vieses que devem ser evitados.

O estudo reforça a idéia de que é possível aplicar a ferramenta do MFV - direcionada originalmente a processos de manufatura - para processos administrativos, trazendo benefícios para estes também. É importante mencionar que um próximo passo de pesquisa seria revisar o mapeamento realizado com a participação de mais representantes das áreas envolvidas no processo, trazendo uma análise mais rica e completa, que resulte na proposição de um mapa do fluxo futuro ainda mais abrangente e consistente.

Por ter focalizado somente um exemplo isolado, com o presente artigo abre-se a possibilidade da realização de investigações mais abrangentes, que proporcionem a extensão das discussões e proposições apresentadas a um espectro mais variado de práticas de mercado.

Vale ressaltar que, além de representar um caminho de melhoria para o processo de mudança de forecast de pro- 


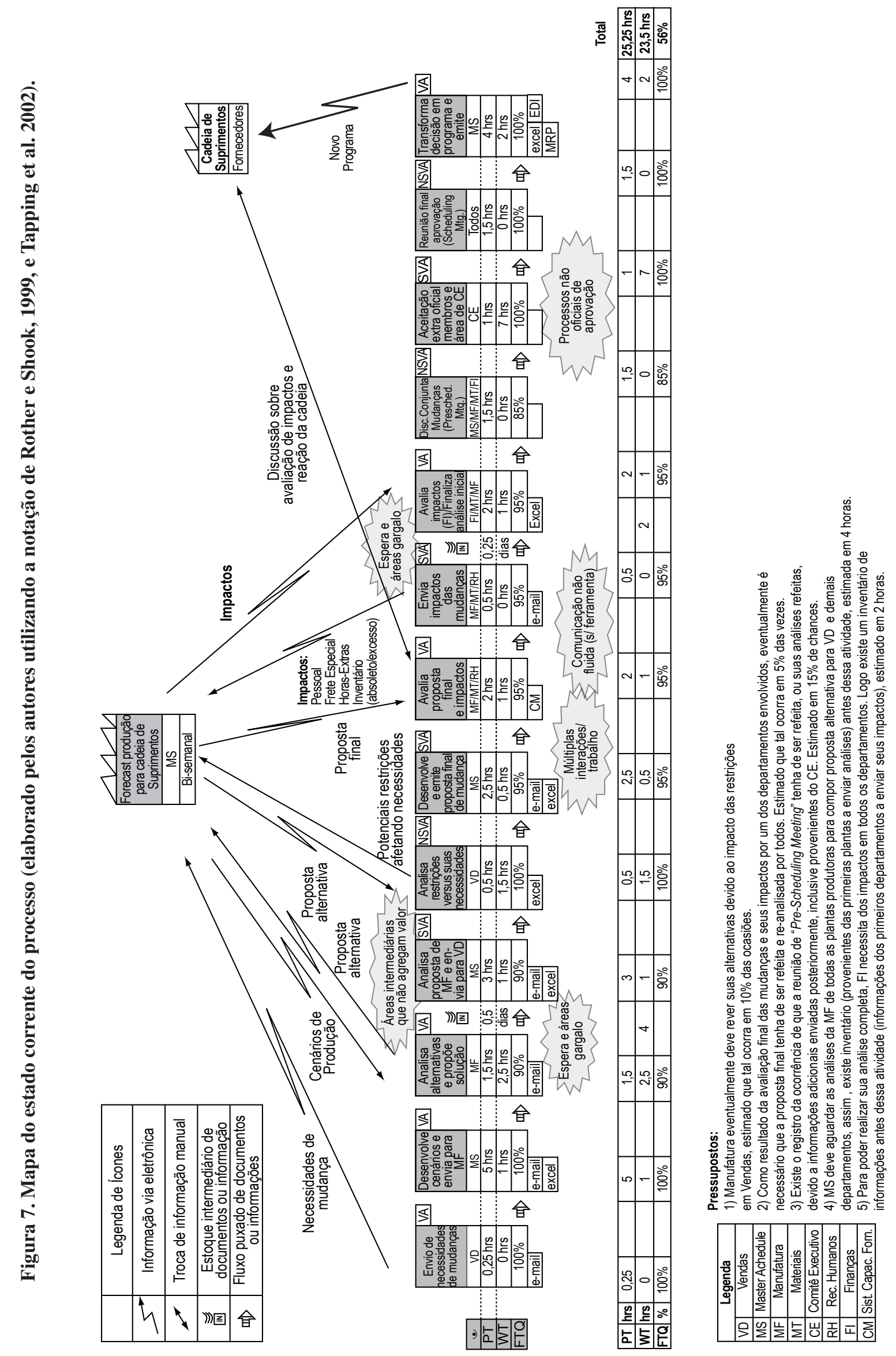




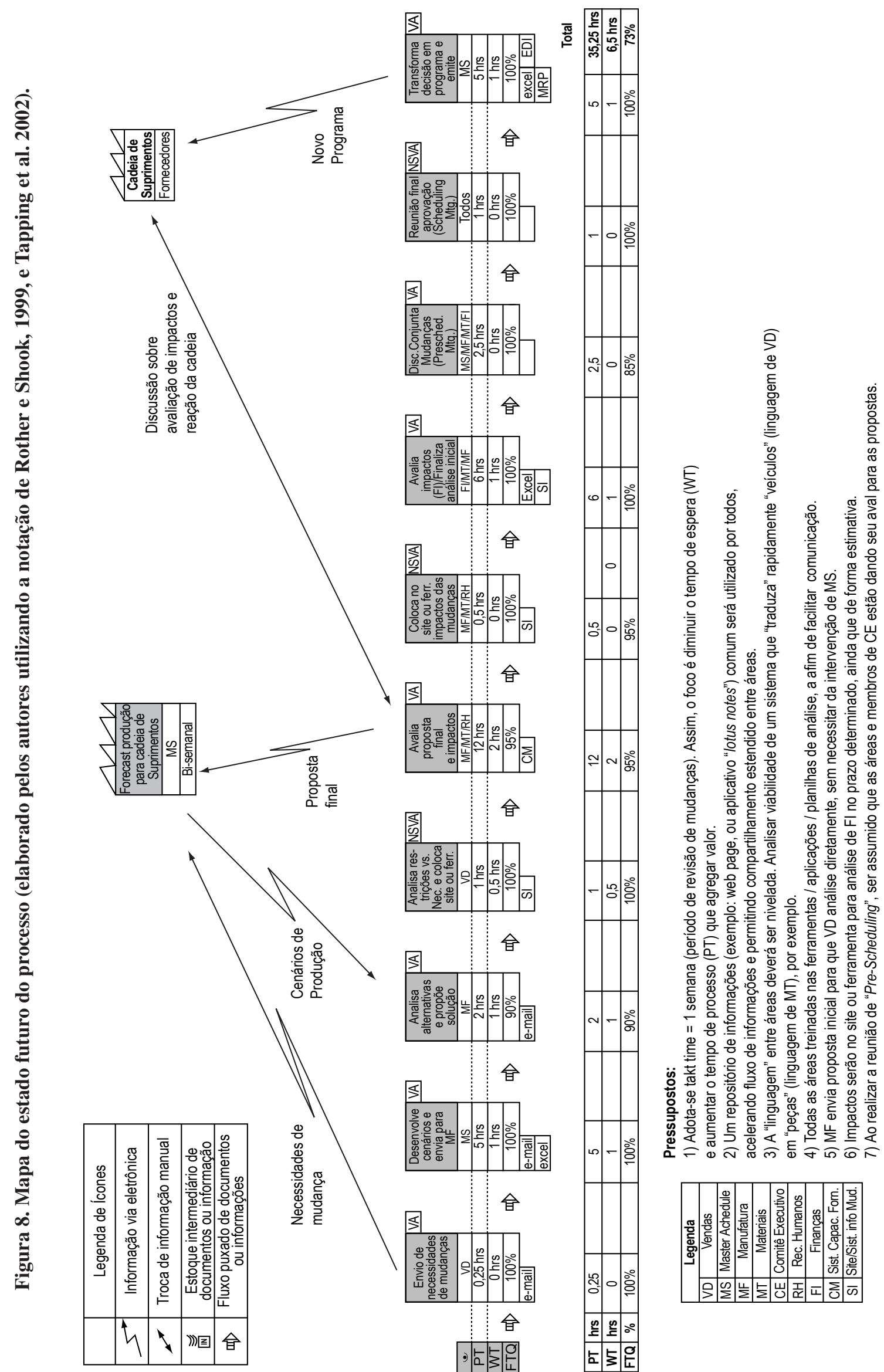




\begin{tabular}{|c|r|}
\hline \multicolumn{2}{|c|}{ Estado Corrente } \\
\hline SVA & $6,5 \mathrm{~h}$ \\
\hline NSVA & $7,5 \mathrm{~h}$ \\
\hline VA & $11,25 \mathrm{~h}$ \\
\hline WT & $23,5 \mathrm{~h}$ \\
\hline
\end{tabular}
\begin{tabular}{|c|r|}
\hline WT & $6,5 \mathrm{~h}$ \\
\hline VA & $27,25 \mathrm{~h}$ \\
\hline
\end{tabular}
\begin{tabular}{|c|c|}
\hline \multicolumn{2}{|c|}{ Estado Futuro } \\
\hline SVA & $0 \mathrm{~h}$ \\
\hline Redução de $72 \%$ \\
\hline
\end{tabular}

Figura 9. Melhoria do valor das atividades. dução na indústria automobilística, a abordagem analítica proposta pode ser estendida ao tratamento dos impactos decorrentes destas mudanças ao longo da cadeia de suprimentos. A perniciosa amplificação das variações, por meio dos elos da cadeia, seria um dos impactos que podem ser abordados de modo a se buscar um processo de mudança mais racional que promova maior estabilidade.

\section{Referências Bibliográficas}

BAZERMAN, M. H. Judgement in managerial decision making. 3 ed. New York: John Wiley \& Sons, 1994.

BRONZO, M. Relacionamentos colaborativos em redes de suprimentos. Revista de Administração de Empresas, São Paulo, v. 44, p. 61-73, edição especial Minas Gerais, 2004.

CHAPPELL, L. The future's not here. Automotive News, 02 de agosto de 2004. Disponível em: <http://www.autonews.com>. Acesso em: 26 de Outubro de 2004.

CLEMEN, R. T.; REILLY, T. Making hard decisions with decision tools suite. Belmont: Duxbury, 2001.

FINE, C. H. Mercados em evolução contínua - Conquistando vantagem competitiva num mundo em constante mutação. Rio de Janeiro: Campus, 1999.

GUYER, L. Five holy grails of IT. Automotive News, 08 de outubro de 2004. Disponível em <http://www.autonews. com>. Acesso em: 24 de Outubro de 2004.

HINES, P., et al. Value stream management - Strategy and excellence in the supply chain. Great Britain: Prentice Hall, 2000.

HOLWEG, M.; PIL, F. K. Successful build-to-order strategies start with the customer. MIT Sloan Management Review, Cambridge, Massachusetts, v. 43, n. 1, p. 74-83, fall, 2001.

JONES, D. T.; HINES, P.; RICH, N. Lean logistics. International Journal of Physical Distribution \& Logistics Management, Glendale, Arizona, v. 27, n. 3-4, p. 153$173,1997$.

MARCH, J. G.; SHAPIRA, Z. Managerial perspectives on risk and risk taking. Management Science, Linthicum, Maryland, v. 33, issue 11, p. 1404-1418, Nov 1987.

MILLER, J. Honda e Toyota se distanciam na liderança de eficácia produtiva. Jornal Gazeta Mercantil, São Paulo, 15 de junho de 2004. Caderno A, p. 6.
OHNO, T. O sistema Toyota de produção - Além da produção em larga escala. Porto Alegre: Bookman, 1997.

ROTHER, M.; SHOOK, J. Aprendendo a enxergar - mapeando o fluxo de valor para agregar valor e eliminar o desperdício. São Paulo: Lean Institute Brasil, 1999.

SALERNO, M. S.; MARX, R.; ZILBOVICIUS, M. Strategies of product design, production and suppliers selection in the auto industry: Final findings of a broad research in the major brazilian assembler's subsidiaries, headquarters and suppliers. In: 11th GERPISA International Colloquium, Junho 2003, Paris. Abstracts and papers. Disponível em: <http://www.gerpisa.univ-evry.fr/gerpisa_index.html>.

SHAPIRO, J. F. Modeling the supply chain. Pacific Grove, California: Duxbury, 2001.

SLACK, N. Vantagem competitiva em manufatura. São Paulo: Atlas, 1993.

TAPPING, D.; SHUKER, T. Value stream management for the lean office. New York: Productivity Press, 2002.

THE ECONOMIST. Survey: Fighting back. London: The Economist, Sept. 4, 2004, p. 10.

TYNDALL, G., et al. Supercharging supply chains - New ways to increase value through global operations excellence. New York: John Wiley \& Sons, 1998.

WILDING, R. D. Chaos Theory: Implication for Supply Chain Management. The International Journal of Logistics Management, Columbus, Ohio, v. 9, n. 1, p. 4356, 1998.

WOMACK, J. P.; JONES, D. T. Lean thinking - Banish waste and create wealth in your corporation. New York: Simon \& Schuster, 1996.

WOMACK, J. P.; JONES, D. T.; ROSS, D. A máquina que mudou o mundo. Rio de Janeiro: Campus, 1992. 


\title{
CHANGES IN AUTOMOTIVE INDUSTRY FORECASTING: INITIATIVES FOR STRUCTURING THE PROCESSES OF DECISION-MAKING AND INFORMATION PROCESSING
}

\begin{abstract}
This paper identifies the aspects of the current literature on the decision-making process and Value Stream Mapping (VSM) - a tool derived from the lean thinking approach - that can be applied to improve the process of production forecast changes in the automotive industry. The theoretical propositions and their methodological implications are discussed from the practical viewpoint, focusing on the real case of an auto manufacturer in the Brazilian market. Recommendations are made to improve this process and make it clear, objective and rational, as well as to strengthen the competitiveness of this industry and its supply chain. The idea of combining the application of VSM adapted to administrative environments and processes with suggestions based on normative and descriptive theories about decision-making engineering seems promising and may contribute to improve the quality and efficiency of this process.
\end{abstract}

Keywords: supply chain management, decision-making process, value stream mapping, automotive industry, Brazil. 